\title{
Response and resilience of soil microbial communities inhabiting in edible oil stress/contamination from industrial estates
}

\author{
Vrutika Patel ${ }^{1}$, Anukriti Sharma², Rup Lal ${ }^{2}$, Naif Abdullah Al-Dhabi ${ }^{3}$ and Datta Madamwar ${ }^{1 *}$
}

\begin{abstract}
Background: Gauging the microbial community structures and functions become imperative to understand the ecological processes. To understand the impact of long-term oil contamination on microbial community structure soil samples were taken from oil fields located in different industrial regions across Kadi, near Ahmedabad, India. Soil collected was hence used for metagenomic DNA extraction to study the capabilities of intrinsic microbial community in tolerating the oil perturbation.

Results: Taxonomic profiling was carried out by two different complementary approaches i.e. 165 rDNA and lowest common ancestor. The community profiling revealed the enrichment of phylum "Proteobacteria" and genus "Chromobacterium," respectively for polluted soil sample. Our results indicated that soil microbial diversity (Shannon diversity index) decreased significantly with contamination. Further, assignment of obtained metagenome reads to Clusters of Orthologous Groups (COG) of protein and Kyoto Encyclopedia of Genes and Genomes (KEGG) hits revealed metabolic potential of indigenous microbial community. Enzymes were mapped on fatty acid biosynthesis pathway to elucidate their roles in possible catalytic reactions.

Conclusion: To the best of our knowledge this is first study for influence of edible oil on soil microbial communities via shotgun sequencing. The results indicated that long-term oil contamination significantly affects soil microbial community structure by acting as an environmental filter to decrease the regional differences distinguishing soil microbial communities.
\end{abstract}

Keywords: Oil perturbation, $\beta$-proteobacteria, $16 \mathrm{~S}$ rRNA gene, Bacterial community structure, Fatty acid biosynthesis, Enzymes

\section{Background}

Oil spills have been pivotal in delineating microbial diversity at the affected site in contrast to the pristine soil. Thus, it becomes important to understand how indigenous microbial communities respond to the stress in order to understand their role in degradation process. Implementation of efficacious bioremediation strategies relies on innate microbial community dynamics, structure, and function [1]. Depending on biotic and abiotic factors, microorganisms adapt to the environment and accordingly environmental conditions select for microorganisms

\footnotetext{
* Correspondence: datta_madamwar@yahoo.com

'Post Graduate Department of Biosciences, Centre of Advanced Study in Bioresource Technology, Sardar Patel University, Satellite Campus, Vadtal Road, Bakrol 388 315, Gujarat, India

Full list of author information is available at the end of the article
}

featuring specific capabilities. Other environmental variables also influence microbial distribution, such as regional climate $[2,3]$ soil type and characteristics $[4]$ and vegetation [5].

Interestingly, microbial community interacts with each other to adapt under extreme environmental changes via modulating genome architecture [6, 7]. The vast majority of these organisms have been characterized through culture-independent molecular surveys using conserved marker genes like the small subunit ribosomal RNA or more recently the shotgun sequencing $[8,9]$. The ongoing development of next generation sequencing (NGS) methods can now be combined with advanced bioinformatics method to replace more traditional approach of metagenomic library screening [10-12]. Consequently, more and more complete microbial genomes as well as 
environmental metagenomes are being sequenced to gain insights into functional aspects besides species composition [13].

Till date microbial community studies in oil-polluted sites have been carried out either for crude oil contamination (marine and coastal sites) [14-16] or petroleum oil contamination $[17,18]$ or desert soils $[19,20]$ but limited efforts have been made in the direction of studying role of bacterial community at sites tainted with edible oil. Consequently, the intrinsic microbial community has to be active degrader organic pollutants (fats and lipids). The process of biodegradation mainly depends on microorganisms which enzymatically attack the pollutants and convert them into innocuous products [21]. Major group of extracellular hydrolytic enzymes disrupt chemical bonds in the toxic molecules and results in the reduction of their toxicity. This mechanism is effective for biodegradation of oil spill as well as organophosphate and carbamate insecticides. Bacteria such as Bacillus sp., Pseudomonas sp., Chromobacterium vinosum and the fungi Aspergillus niger and Humicola lanuginose, Rhizopus delemar and Candida rugosa secrete hydrolytic enzyme i.e. lipase that hydrolyse triacylglycerides to fatty acids and glycerol [22] and catalyze the degradation of lipids. Recent reports have shown that lipase activity is closely related with organic pollutants present in the soil and for the drastic reduction of total hydrocarbon from contaminated soil. Hence, research undertaken in this area is likely to progress the knowledge in the bioremediation of oils spill [23].

The study aims at the metagenomic-analysis of the microbial community inhabiting long-term edible oil contaminated site for both taxonomic profile and catabolic gene potential. Taxonomic profiling will provide insights into the composition of the microbial community capable of tolerating and/or degrading fatty acid compounds. Functional characterization of metagenome sequence reads on the basis of Clusters of Orthologous Groups of proteins (COG) accessions and Kyoto Encyclopedia of Genes and Genomes (KEGG) database entries will lead to elucidation of the catabolic potential of the indigenous microbial community. This approach will facilitate identification of genes essential for key catalytic steps in biodegradation pathways with respect to edible oil. Concisely, the obtained data will improve our understanding for the dynamics of bacterial community inhabiting oil stress and will also assess the genomic potential of the indigenous microbial community of the contaminated soil habitat.

\section{Methods}

Survey of the sampling site and physicochemical analysis of soil samples

To study the shift in microbial community structure across the oil polluted sites we collected bulk soil samples from the depots of oil contamination located near industrial area of Kadi, Ahmedabad. Three different sampling sites (i.e. P1, P2, P3) of soil were selected that represents accumulated edible cotton seed oil contamination since 20 years, resulted from oil spillage in ginning mills (GPS location for polluted site 23 degrees 17' 46.2624"N_72 degrees 20'37.2840"E). Another sampling site was located within the industrial estate area 500 meter without any contamination i.e. control soil sample $(\mathrm{C} 1, \mathrm{C} 2, \mathrm{C} 3)$ and was considered as a reference to demonstrate changes in microbial community under oil stress (GPS location for control site 23 degrees 17' 17.1780 "N_72 degrees $21^{\prime} 36.6048^{\prime \prime}$ ). At each site sampling was performed in replicates and collected soil was archived at $4{ }^{\circ} \mathrm{C}$ until further use. Physicochemical analysis of soil samples such as soil moisture, soil texture, organic carbon content, soil carbon/nitrogen ratio (C:N) were determined. This soil sample is collected from the soil where the cluster of edible oil industries are available, does not involve any ethical issues. No prior permission was required as this land does not belong to any specific agency. However, field studies do not create any destruction to endangered or protected species.

\section{Community DNA extraction and sequencing}

Metagenomic DNA from each soil samples i.e. polluted and control (P1, P2, P3, C1, C2 and C3) was extracted using protocol described by Zhou et al. [24]. In all $50 \mu \mathrm{L}$ MilliQ water was used to dissolve DNA at the final step.

Soil sample ( $5 \mathrm{~g}$ ) was pre-washed with double distilled water before DNA extraction according to the method of Zhou et al. [24]. Briefly, after adding $5 \mathrm{~g}$ glass beads $(\mathrm{d}=3 \mathrm{~mm})$ and $15 \mathrm{~mL}$ DNA extraction buffer $(100 \mathrm{mM}$ Tris, $100 \mathrm{mM}$ EDTA, $1.5 \mathrm{M} \mathrm{NaCl}, 10 \%$ Sucrose, $1 \%$ $\mathrm{CTAB}, 100 \mathrm{mM}$ sodium phosphate buffer $\mathrm{pH}=8.0$ ) to the pretreated soil, the sample was vortexed for $5 \mathrm{~min}$ followed by incubation for $30 \mathrm{~min}$ at $37^{\circ} \mathrm{C}$ on environmental shaker. Subsequently, $2 \mathrm{ml}$ SDS (20\%) was added and mixed with hand-shaking for $5 \mathrm{~min}$. The sample was incubated at $60{ }^{\circ} \mathrm{C}$ for $30 \mathrm{~min}$ and inverted every $10 \mathrm{~min}$. Further, $0.5 \mathrm{~g}$ of powdered activated charcoal (PAC) was added and incubated for $30 \mathrm{~min}$ more [25]. After centrifugation at $12000 \mathrm{rpm}$ for $15 \mathrm{~min}$ at room temperature, DNA was extracted with an equal volume of phenol and chloroform-isoamyl alcohol (24:1, v/v), precipitated with isopropanol and washed with $70 \%$ ethanol.

Total DNA concentration and quality was analyzed by NanoDrop spectrophotometer and electrophoresed on $0.8 \%$ agarose gel, respectively. Equal concentration of environmental metagenomic DNA (obtained by Qubit reading) from each subsequent sites were mixed to form a composite genetic pool (i.e. $\mathrm{P} 1+\mathrm{P} 2+\mathrm{P} 3=\mathrm{P}$ and $\mathrm{C} 1+$ $\mathrm{C} 2+\mathrm{C} 3=\mathrm{C}$ ) representing total DNA composition for each site. Isolated DNA was sheared and sized to produce DNA library according to the manufacturer's protocol 
from Ion Xpress ${ }^{\text {th }}$ Plus gDNA Fragment Library Preparation Kit. DNA Sequencing was performed on Ion Torrent PGM platform using sequencing chip 318 to generate short reads with an average insert size of $300 \mathrm{bp}$. All the outsourcing for DNA sequencing was done at Xcelris Lab Pvt Ltd, Ahmedabad, India.

\section{Assembly and taxonomic analysis for sequencing data}

Sequences generated for polluted as well as control sample was assembled individually by MetaVelvet assembler $(1.20 .02)[26,27]$ set at $k=31$, -exp cov = auto, -cov_cutoff $=$ auto and insertion length with standard deviation = $300 \mathrm{bp} \pm 20$. Both raw reads and contigs were used for further analysis. The taxonomic positions of sequenced reads was analysed and studied using two complementary approaches: (1) LCA: classification based on lowest common ancestor using MEGAN [28] and (2) Ribosomal Database Project (RDP) classifier: classification based on 16S rRNA gene sequences. MEGAN platform uses the lowest common ancestor (LCA) algorithm to classify reads to certain taxa based on their blast hits $[29,30]$. The LCA parameters were set as Min Score $=35.0$, Top Percent $=50$, and Min Support $=2$. In addition, the 16S rRNA sequences were extracted from the results of BLASTN analysis against the $\mathrm{nt} / \mathrm{nr}$ database [26] and submitted to the RDP classifier $[29,31]$ with $\mathrm{E}$ value $<1 \times 10^{-1}$ and $80 \%$ confidence level. The RDP classifier predicted the taxonomic origin of 16S rRNA up to the rank of genus. Moreover, in order to rectify diversity picture other reference databases such WebCARMA (based on Environmental gene tags i.e. EGTs) and non-redundant database M5NR were also used with standard parameters.

\section{Rarefaction analysis, Diversity indices and multivariate component analysis}

Rarefaction curve was generated for all reads, except unassigned reads. Species richness was plotted according to the data obtained from RDP dataset [31], whereas, additional species likely to be discovered was addressed by plotting the discovery rate of dataset, which is obtained by repeatedly selecting random subsample of the dataset at 10,20 , upto- $90 \%$ of the original size and then plotting the number of leaves predicted by LCA algorithm using MEGAN [28]. The diversity index i.e. Shannon's evenness index for general diversity (at genus level) and Simpson's dominance index on the basis of genus were calculated as described previously [25, 32, 33]. Multivariate principle component analysis (PCA), contour plot and correspondence analysis plot was plotted using data of phylum in PAST3 software [34].

\section{Mapping of metagenomic reads}

Polluted metagenomic single reads were mapped on available microbial genomes by aligning to the sequenced genome(s). An E-value cut off of $1 \mathrm{Xe}^{-3}$ and $\log _{2}$ as abundance scale was set. The coverage of reference genome sequence by reads was visualized using the Circos $[35,36]$.

\section{Functional characterization and classification of genes}

Functional characterization of reads was done on the basis of assembled data obtained from polluted sample. Gene calling was performed on the contigs using FragGeneScan [37] in order to predict operon reading frame (ORF). The ORFs were functionally annotated and assigned to the Clusters of Orthologous Groups of proteins (COG) [38] with an $\mathrm{E}$ value cut-off $10^{-5}$. The metabolism analysis was performed on KEGG Orthology (KO)-identifiers by using KAAS tool (KEGG Automatic Annotation Server) based on bi-directional best hit approach (60). Gene annotation was based on Enzyme Commission (EC)-numbers based on the Kyoto Encyclopedia of Genes and Genomes (KEGG) Orthology database [39].

\section{Screening of bacterial strains having oil degradation ability}

Soil obtained from polluted sample was serially diluted and spread on Nutrient agar, Luria agar, Plate count agar and Tributyrin agar plates supplemented with tributyrin oil as a carbon source. Bacterial strains were selected on the bases of their ability to hydrolyze tributyrin oil by producing a clear zone around bacterial colonies [22, 40-42]. A total of 40 strains were isolated based on their distinct morphological characteristics of the colonies and hydrolysis of trybutyrin oil. All the isolated culture on plates was observed for $48 \mathrm{~h}$ and sub cultured once in every month. Further, all the bacterial strains were maintained at $4{ }^{\circ} \mathrm{C}$ in pure form for further use.

\section{Data availability}

The sequence data for both soil samples i.e. polluted and control obtained from Ion Torrent PGM platform has been deposited at MGRAST server (version 3). MGRAST IDs for the datasets are 4508969.3 and 4516462.3 for polluted soil and control soil, respectively. MGRAST IDs for the contig obtained from both the samples are 4515485.3 and 4512472.3, respectively. The sequences obtained from the culturable diversity study have been submitted to GenBank, NCBI and their accession numbers are from KR140170 to KR140186 (polluted soil) and KR140187 to KR140201 (control soil).

\section{Results}

Multiple studies have demonstrated the applications of high throughput sequencing in the study of microbial distributions and functional genes in different microbial communities. However, there are limited reports on bacterial community structural studies for edible oil contamination sites. Therefore, we took this opportunity to 
explore effect of oil on bacterial community shift in long term edible oil-contaminated sites from industrial area of Kadi, Ahmedabad. Innate microbial community inhabiting contaminated environment was analyzed in terms of its composition and diversity by high-throughput shotgun sequencing approach via ion-torrent PGM platform provided by Xcelris Lab Pvt Ltd, Ahmedabad, India.

\section{Physicochemical analysis of soils}

The physicochemical analysis of soil samples from both (control and polluted) sites are tabulated in Table 1 showing significant difference $(P$-value $<0.05)$ in all the corresponding parameters. Soil with oil stress exhibited higher nitrogen (1.5 times) and potassium (1-3 times) content as compared to that of control soil sample. This difference could be attributed to the characteristic feature of soil ecosystems with inherent bioremediation potential [43]. Total organic carbon was found to be $1.05 \%$ and $0.71 \%$ for polluted and pristine soil, respectively.

\section{Metagenomic DNA extraction and analysis}

Soil collected from the industrial area was used for metagenomic DNA extraction using the protocol of Zhou et al. [24]. The obtained DNA was of high molecular weight (Additional file 1: Figure S1) and was pure enough for further sequencing studies. Details about purity ratio and quality of metagenomic DNA (after pooling up DNA for each respective site i.e. $\mathrm{P}$ and $\mathrm{C}$ ) with respect to humic acids is described in Table 1.

Sequencing of two DNA libraries (viz. polluted soil and control soil) was performed and data from the experiments are summarized in Table 2 . The sequencing run resulted in 17, 06,040 reads (an average read length of $339 \mathrm{bp}$ ) for polluted sample and 39,98,015 reads (an average read length of $356 \mathrm{bp}$ ) for control sample. In total $31,284,971$ numbers of bases were assembled into 201,285 contigs for polluted soil and 58,039,898 number

Table 1 Characteristics features of sample for both polluted and control soil

\begin{tabular}{llll}
\hline Sr. No & Parameters tested & Polluted soil & Control soil \\
\hline 1 & Texture of soil & Fine loamy soil & Fine loamy soil \\
2 & Temperature $\left({ }^{\circ} \mathrm{C}\right)$ & 37 & 37 \\
2 & $\mathrm{pH}$ & 8.10 & 8.26 \\
3 & Organic carbon $(\%)$ & 1.05 & 0.71 \\
4 & Total Nitrogen $\left(\mathrm{Kgha}^{-1}\right)$ & 2070 & 1371 \\
5 & Available $\mathrm{P}_{2} \mathrm{O}_{5}\left(\mathrm{Kgha}^{-1}\right)$ & 37.75 & 26.78 \\
6 & Available $\mathrm{K}_{2} \mathrm{O}\left(\mathrm{Kgha}^{-1}\right)$ & 170.45 & 122.21 \\
7 & EC $\left(\mathrm{dSm}{ }^{-1}\right)$ & 0.33 & 0.19 \\
8 & DNA concentration $(\mathrm{ng} / \mathrm{\mu L})$ & 404 & 358 \\
\hline
\end{tabular}

Table 2 Summary of sequencing result

\begin{tabular}{lll}
\hline & Polluted & Control \\
\hline Number of reads & $17,06,040$ & $39,98,015$ \\
Average read length & 339 & 356 \\
Total number of contigs & 201,285 & 262,608 \\
Max contig length & 1347 & 1258 \\
Number of bases in contigs & $31,284,971$ & $58,039,898$ \\
N50 & 157 & 221 \\
\hline
\end{tabular}

The sequences were assembled separately using MetaVelvet assembler

of bases were assembled into 262,608 contigs for control soil sample using MetaVelvet assembler [26, 27].

\section{Bacterial diversity analysis}

The taxonomic positions of sequenced reads was analysed and studied using two complementary approaches: (1) LCA: classification based on lowest common ancestor using MEGAN [28] and (2) RDP classifier: classification based on 16S rRNA gene sequences [31]. The predominance of bacterial reads was equally observed in all two approaches used to characterize indigenous bacterial community structure with RDP suggesting $97 \%$ dominance of bacteria and $98 \%$ reads were accounted to bacteria in LCA for perturbed environment.

Since $16 \mathrm{~S}$ rRNA is widely used for taxonomic and phylogenetic studies due to its highly conserved sequences, its hypervariable region can also be used for accurate taxonomic evaluation [44]. The reads assigned to the superkingdom Bacteria are $\sim 97.6 \%$ for polluted and $\sim 95.8 \%$ in pristine indicating dominance of domain bacteria. The niche generated due to perturbed environment was dominated by phylum Proteobacteria (60.9\%), followed by Bacteroidetes (5.6 \%) responsible for lipid metabolism. Only $30 \%$ of Proteobacteria and $7.4 \%$ of Bacteroidetes was dominant in control sample. The 3rd most abundant taxon in both samples (i.e. polluted and control) is Verrucomicrobia ( $2.4 \%$ and $4.3 \%$ ) which was followed by Firmicutes (0.6 \% and $4.2 \%)$ and Actinobacteria (1.3\% and $3.4 \%)$, respectively (Additional file 1: Figure S2).

At the class level community shift can be clearly seen between polluted and control soil samples. Gammaproteobacteria (14.9 \%) showed dominancy in control soil while Betaproteobacteria (56.3 \%) is in abundance for polluted soil sample (Fig. 1). The second most abundant class found in polluted soil is Sphingobacteria (2.5\%) followed by Gammaproteobacteria (2.2\%), Cytophagia $(2 \%)$ and Verrucomicrobiae (1.4\%). Betaproteobacteria (6\%) was found to be second dominant class in control soil sample followed by Alphaproteobacteria (5\%), Actinobacteria (3.5\%), Deltaproteobacteria (3.3\%), Flavobacteria (2.9\%) and Verrucomicrobiae (2.7\%). At rank genus Chromobacterium (45.5\%) (family Neisseriaceae) showed dominancy for polluted sample followed by 


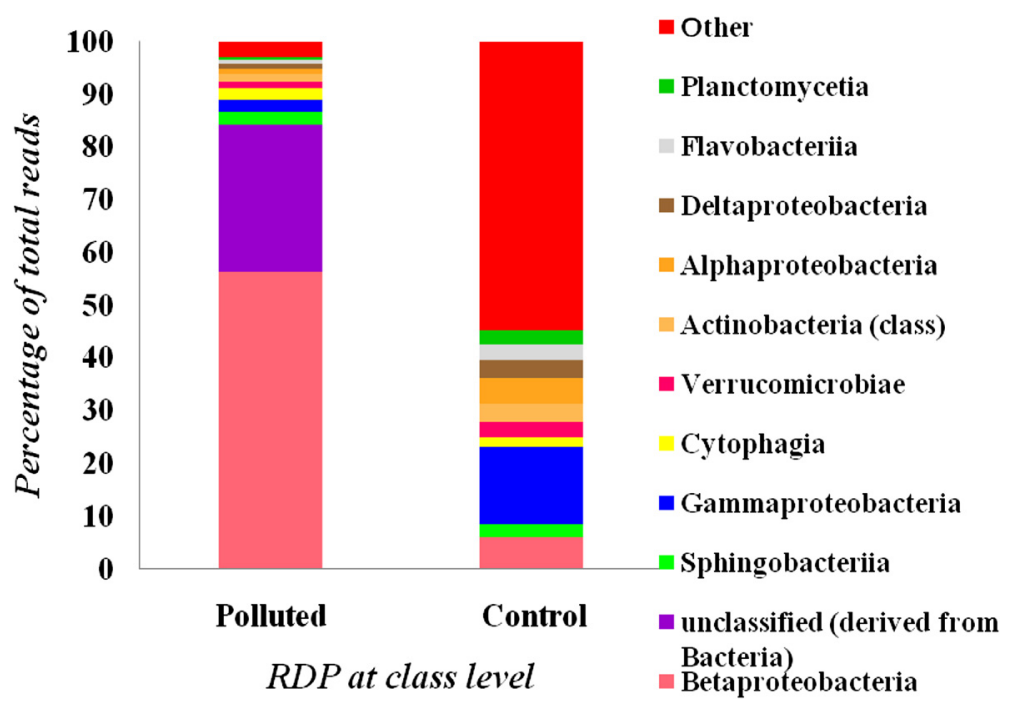

Fig. 1 Distribution of taxa among bacteria at rank class classified according to 165 rDNA using RDP classifier for both polluted as well as control sample

Neisseria (4.9\%) (family Neisseriales), Cupriavidus (4.5\%) (family Burkholderiaceae) and Pedosphaera (1.06 \%) belonging to the family Verrucomicrobia. Genus Klebsiella (5\%) (family Enterobacteriaceae) was found to be abundant in control sample followed by $2.2 \%$ Flavobacterium (family Flavobacteriaceae), 1.7 \% Brevibacillus (family Paenibacillaceae) and $1.6 \%$ Xantomonas (family Xanthomanadaceae). (Data for genus level is not shown)

Meanwhile, we also analyzed microbial community compositions based on lowest common ancestor (LCA). The statistics for both the sample (i.e. polluted and control) are shown in Additional file 1: Figure S3 at rank phylum. However, data for only polluted sample is explained in text. Comparable to the taxonomic structure generated from the output on reads, our analysis revealed that polluted soil sample showed Proteobacteria (47 \%), followed by Bacteroidetes (20\%), Verrucomicrobia (15.5\%), Plantomycetes (4 \%) and Acidobacteria (3\%) as most dominant classified phylum (Additional file 1: Figure S3). For polluted site the dominant classes (Fig. 2) in bacteria are Alphaproteobacteria (19\%), Betaproteobacteria (13\%), Gammaproteobacteria (7\%), Spartobacteria (7 \%) and Cytophagia (7 \%). At rank genus Chthoniobacter (10 \%) (family unclassified from

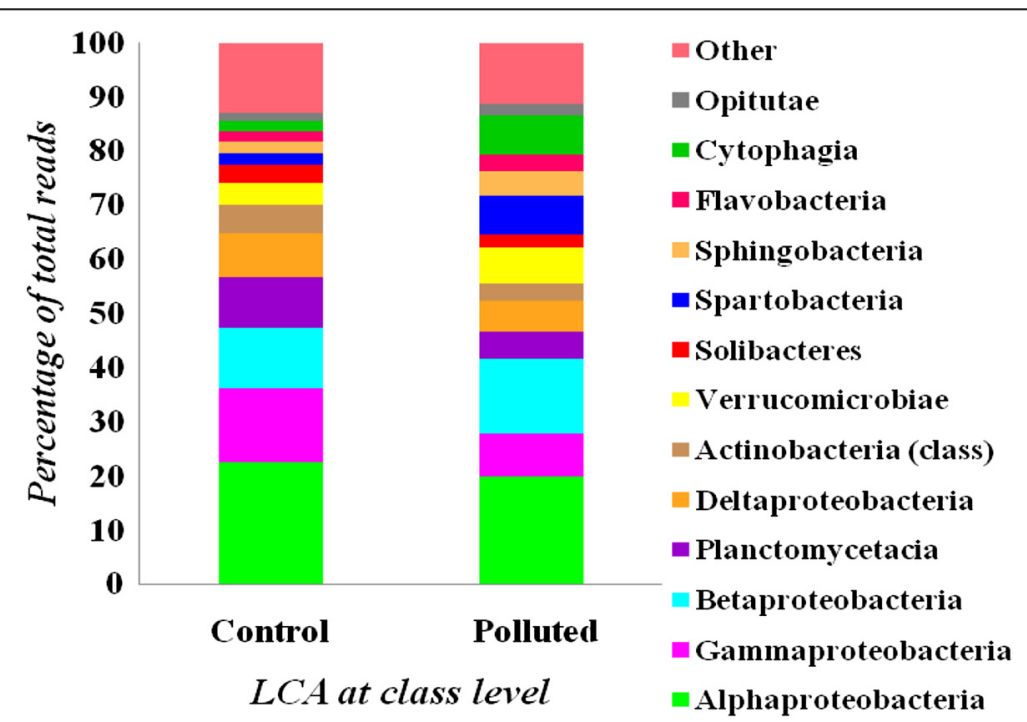

Fig. 2 Distribution of taxa among bacteria at rank class classified according to lowest common ancestor (LCA) for both polluted as well as control sample 
Spartobacteria), Chromobacterium (7 \%) (family Neisseriaceae) showed dominancy for polluted sample followed by Candidatus Solibacter (3.5\%) (family Solibacteraceae), Verrucomicrobium (2.9 \%) (family Verrucomicrobiaceae) and Chitinophaga (2.8 \%) belonging to the family Sphingobacteriales.

In addition to this, the diversity picture for both samples was also compared with EGTs using WebCARMA algorithm and non-redundant database M5NR. The comparison is not described in text but displayed through figures in Additional file 1: Figure S4. Among all the databases used for analysis we found that there is influence of oil contamination on soil and can be clearly seen by the dominance of betaproteobacteria at class level and Chromobacterium (widely known for its oil degrading capability) at genus level.

\section{Comparison of microbial composition between soil samples}

Statistical analysis of biodiversity provides interesting insights as reflected in rarefaction curves. Rarefaction analysis was carried out in order to assess species richness of the system. Using RDP, we analyzed the microbial richness, based on sequence reads, between libraries of polluted and control soil samples (Fig. 3a). Whereas, plotting the number of leaves predicted by LCA algorithm revealed that the number of taxonomic leaves or clades of control soil are all higher than those of polluted ones. Also, control and polluted soil contains 629 and 396 leaves for all assigned taxa, respectively (Fig. 3b). Furthermore, the rarefaction curves of both libraries appear close to saturation at $100 \%$ of the total reads. Our results suggest that the current sampling depth is not yet close to the natural status for bacteria.

Shannon index was used to indicate diversity and complexity, and the Simpson index was used to measure abundance. As exhibited in Fig. 3c, the lowest Shannon diversity in polluted sample indicates presence of phylotypes while in control sample the diversity indices showed a higher level of species richness. Simpson index showed the dominance in polluted sample as compared to that of control. Consistently, the data collected from phylotype distributions of $16 \mathrm{~S}$ rRNA gene sequences of total bacterial community of both the samples were treated by PCA plot, contour plot and correspondence analysis (CA) plot in order to check differences between the sites in terms of bacterial community structures. The entire three analysis viz. PCA plot, Contour plot and CA plot (Fig. 3d $(a, b, c)$ ) was able to separate control site from that of polluted ones. The data set of both the samples showed that sites were well separated from each other and as well as no cluster formation showed difference in bacterial community structure.

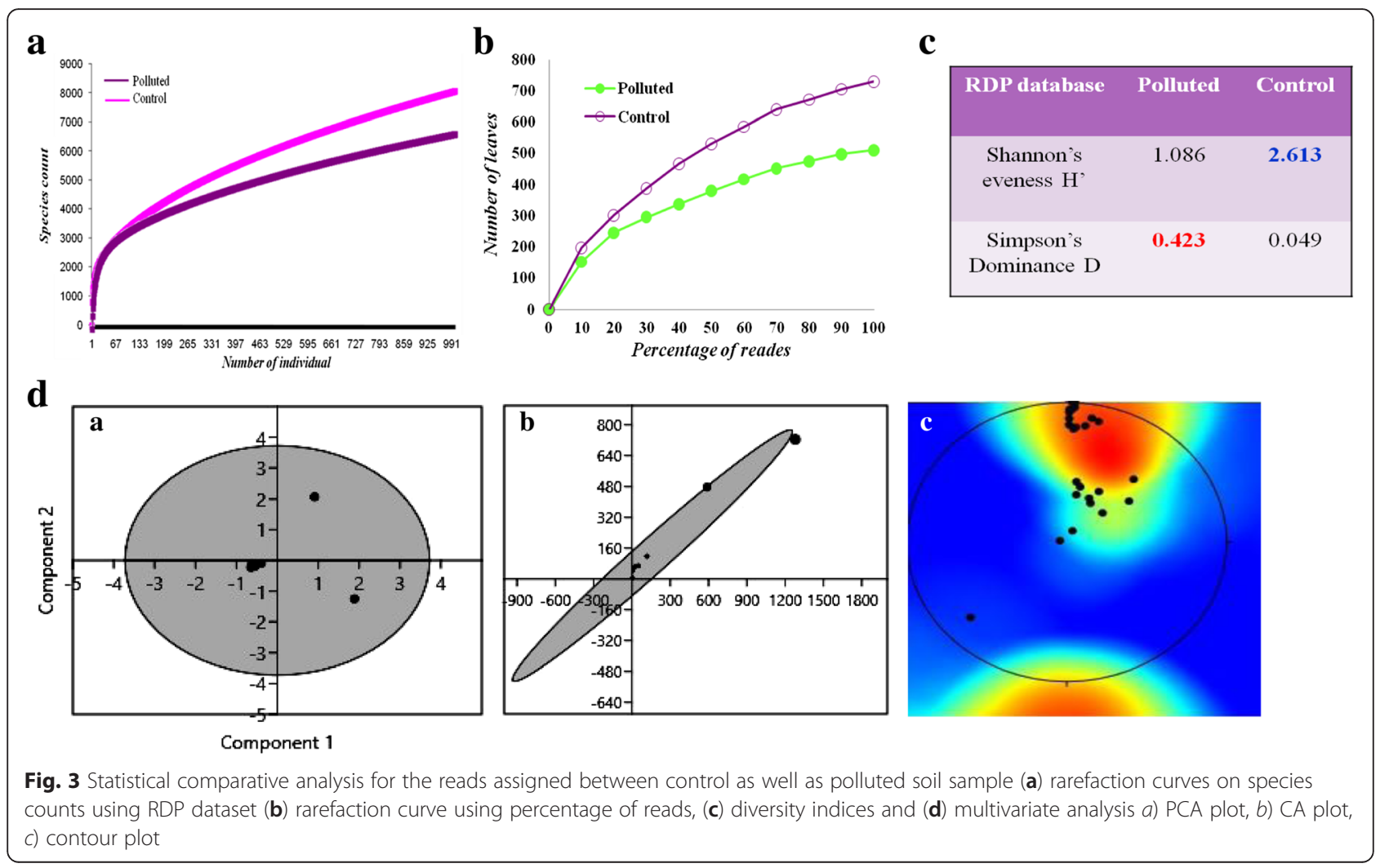




\section{Annotation and mapping of metagenome single reads to the microbial genomes}

Metagenomic reads of polluted sample were mapped for assessing genome coverage. Maximum hits for metagenome were attributed to the genome of Candidatus solibacter ellin (Fig. 4a). Maximum identity percentile of metagenomic reads with whole genome of Candidatus solibacter ellin was found to be $5.76 \%$. List of top 50 microorganisms mapped with highest number of reads are shown in Fig. 4b. The highest number of reads was allocated to Chthoniobacter flavus Ellin428 genome followed by Chitinophaga penensis DSM2588, Candidatus solibacter usitatus Ellin6076, Verrucomicrobium spinosum DSM4136, Spirosoma lingual, Optitutus terrae PB90-1, Dyadobacter fermentans DSM18053, Marivirga tractuosa DSM4126. The list also includes Algoriphagus, Sorangium, Pirellula, Mesorhizobium, Halangium, Cytophaga and others. This suggested that these organisms were enriched at polluted site and can play significant role in fatty acid metabolism and synthesis.

\section{Gene function annotation and classification}

Metabolic profile for bacterial community structure of polluted soil sample was annotated using COG and KEGG databases. Assembled contigs were analyzed by assigning predicted functions to genes based on COG [45]. In total 22 classes based on functional categories were identified by COG database (Fig. 5). In the category "metabolism" large amount of reads are distributed among "amino acid transport and metabolism (E)", "energy production and conversion (C)", "carbohydrate transport and metabolism (G)", and "lipid transport and metabolism (I)". The class "lipid transport and metabolism (I)" was further characterized for various kinds of enzymes responsible for fatty acid metabolism under stress conditions. Classes such as "inorganic ion transport and metabolism (P)" and "coenzyme metabolism $(\mathrm{H})$," "secondary metabolites biosynthesis, transport, and catabolism (Q)," and "signal transduction mechanisms (T)" are associated with transport of ions/compounds and other metabolic processes (Fig. 5). COG categories/ accessions important in lipid metabolism are described in Table 3. In the KEEG analysis, metabolism term including carbohydrate metabolism, lipid metabolism, metabolism of cofactors and vitamins, amino acid metabolism and metabolism of other amino acids are among the top five most popular categories (Fig. 6a). KEGG terms in lipid metabolism are displayed in Fig. 6b. The enzymes involved in lipid metabolism were detected in reads assigned to fatty acid biosynthesis, glycerophospholipid metabolism, sphingolipid metabolism, glycerolipid metabolism as the four most dominant groups which are involved in the processing of lipids and fatty acids. The 20 most abundant enzymes mapped according to KEGG

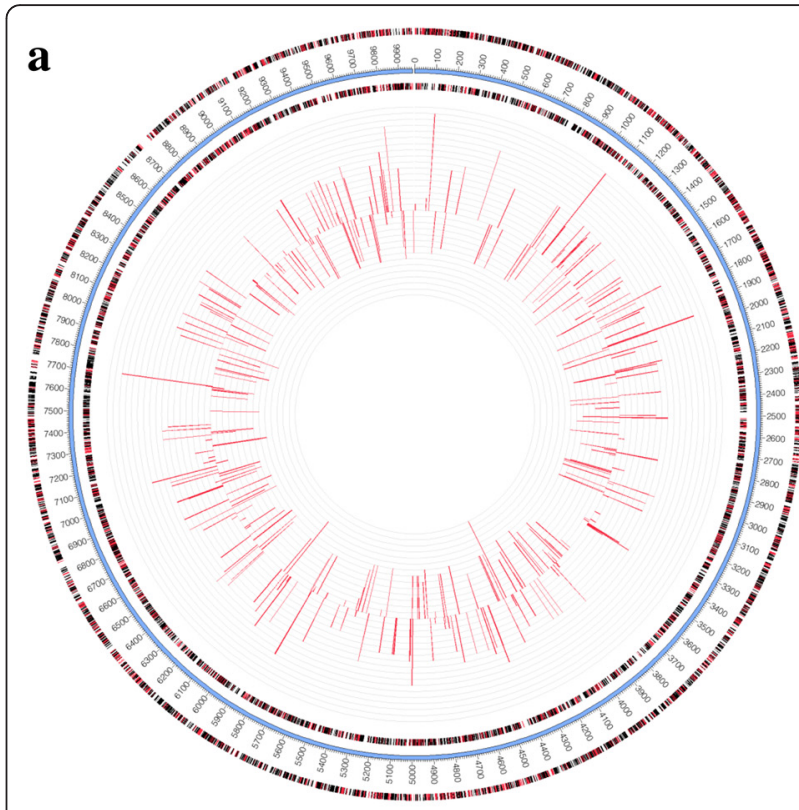

b

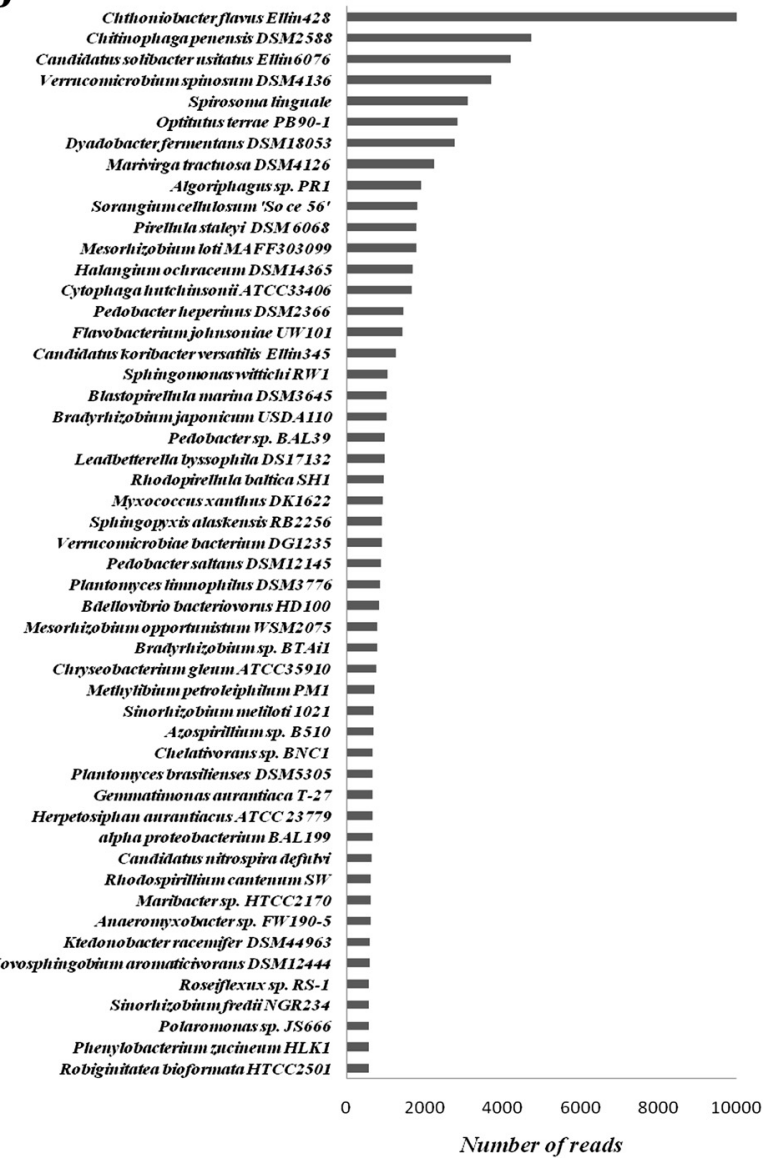

Fig. 4 a Mapping of metagenomic reads from polluted soil sample on the genome of Candidatus solibacter ellin 6076 and $\mathbf{b}$ Metagenomic reads assigned to microbial genomes sequences. The $x$-axis denoted the number of reads assigned to the 50 most prevalent microbial strain genomes 


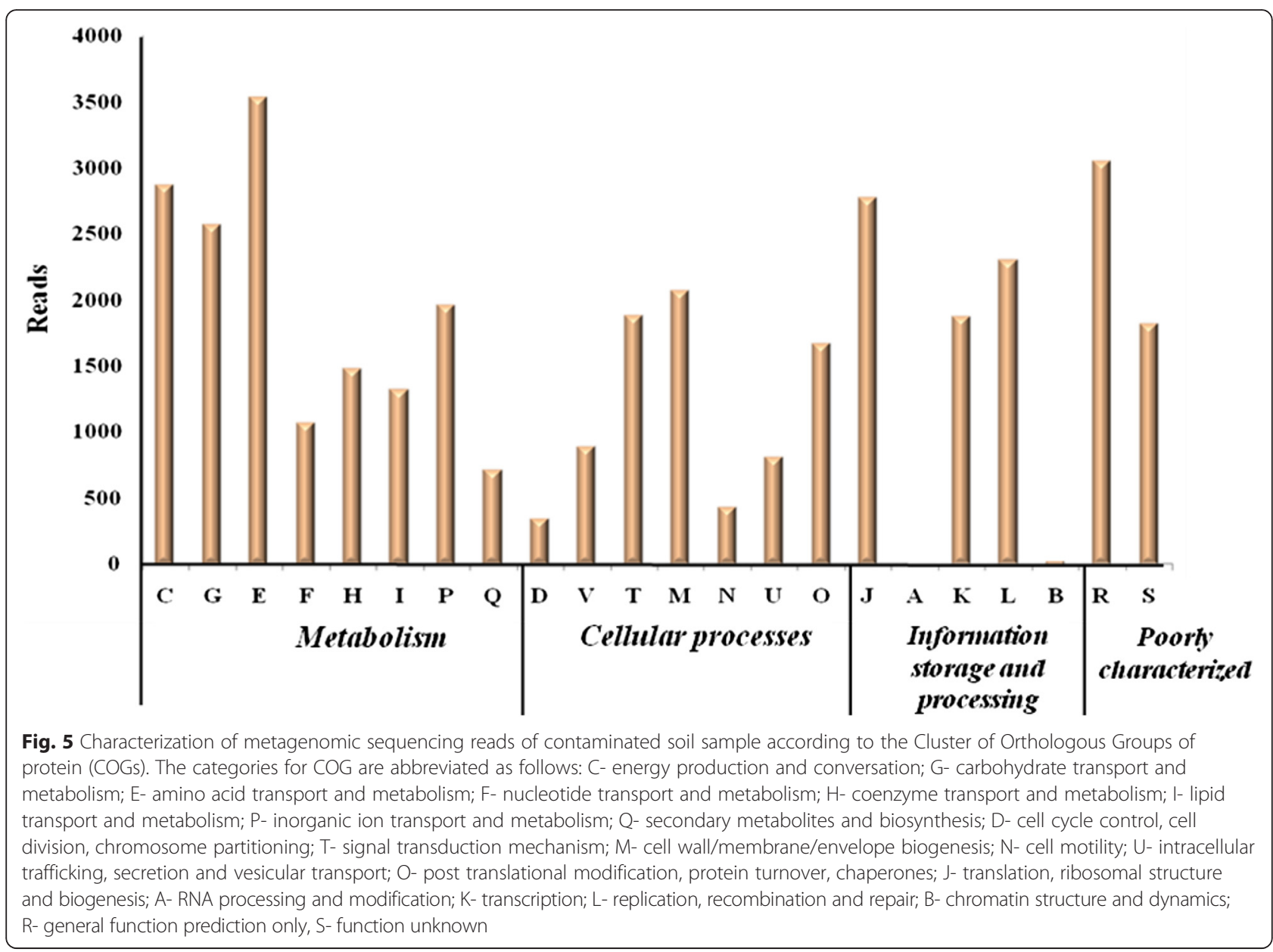

database from metagenomic data is tabulated in Table 4. This observation is consistent with the findings that many species in polluted sample are involved in fatty acid biosynthesis and fatty acid metabolism.

The main focus of the study was on fatty acid biosynthesis. The expression of genes involved in lipid metabolism pathways such as fatty acid biosynthesis (PATH: ko00061), fatty acid degradation (PATH: ko00071) mapped from KEEG database are displayed in Additional file 1: Table S1.

\section{Bacterial community structure using culture dependent approach}

Since the contaminated site of the study is oil perturbed soil attempts were made to isolate organisms on tributyrin agar plates containing tributyrin oil as carbon source. Total bacterial counts of $1.8 \times 10^{2} \mathrm{CFU} / \mathrm{mL}$ were obtained from oil contaminated soil whereas $<30$ bacterial counts were obtained from control sample when screened on tributyrin agar plates. The possible reason for this could be production of extracellular enzymes by particular microorganisms to combat these stressed condition in such contaminated environment. Different species of Bacillus such as (B. subtilis, B. methylotrphicus, B. pumilis, B. endophyticus), Pseudomonas (P. stutzeri, P. sp) as well as Exiqobacterium (E. profundum) known for their lipolytic activities were identified.

\section{Discussion}

Deciphering bacterial community structure using shotgun sequencing approach

Novel technologies continue to expand our understanding of microbial diversity and community structure. Metagenomic analysis [10, 45] has previously identified 'unexpectedly' high bacterial phylogenetic and functional diversity. The long-term sustainability of soil contamination requires detailed knowledge of its biodiversity coupled to profound understanding for its functioning. Previous studies with $16 \mathrm{~S}$ rRNA-based analyses using clone libraries [46-48], microarrays (for example, PhyloChip and GeoChip) [49-52], pyrosequencing [7, 53] and other approaches [54] showed that soil microbial communities are highly diverse and complex.

Here, we took opportunity to explore microbial diversity and its functioning in edible oil contaminated soil using $16 \mathrm{~S}$ rRNA shotgun sequencing approach. This study 
Table 3 COG categories as discovered from the metagenomic reads for lipid metabolism

\begin{tabular}{|c|c|}
\hline COG No. & Name of the protein \\
\hline COG3425 & 3-hydroxy-3-methylglutaryl CoA synthase \\
\hline COG0304 & 3-oxoacyl-(acyl-carrier-protein) synthase \\
\hline COG0332 & 3-oxoacyl-[acyl-carrier-protein] synthase III \\
\hline COG4247 & 3-phytase (myo-inositol-hexaphosphate 3-phosphohydrolase) \\
\hline COG1211 & 4-diphosphocytidyl-2-methyl-D-erithritol synthase \\
\hline COG0439 & Biotin carboxylase \\
\hline COG2272 & Carboxylesterase type B \\
\hline COG4589 & CDP-diglyceride synthetase \\
\hline COG1024 & Enoyl-CoA hydratase/carnithine racemase \\
\hline COG0821 & $\begin{array}{l}\text { Enzyme involved in the deoxyxylulose pathway of isoprenoid } \\
\text { biosynthesis }\end{array}$ \\
\hline COG0657 & Esterase/lipase \\
\hline COG1398 & Fatty-acid desaturase \\
\hline COG1022 & Long-chain acyl-CoA synthetases (AMP-forming) \\
\hline COG3127 & Lysophospholipase \\
\hline COG1443 & Isopentenyldiphosphate isomerase \\
\hline COG2185 & $\begin{array}{l}\text { Methylmalonyl-CoA mutase, C-terminal domain/subunit } \\
\text { (cobalamin-binding) }\end{array}$ \\
\hline COG1260 & Myo-inositol-1-phosphate synthase \\
\hline COG2867 & Oligoketide cyclase/lipid transport protein \\
\hline COG0558 & Phosphatidylglycerophosphate synthase \\
\hline COG1562 & Phytoene/squalene synthetase \\
\hline COG3243 & Poly(3-hydroxyalkanoate) synthetase \\
\hline COG4553 & Poly-beta-hydroxyalkanoate depolymerase \\
\hline COG1657 & Squalene cyclase \\
\hline COG0020 & Undecaprenyl pyrophosphate synthase \\
\hline
\end{tabular}

provides a comprehensive survey of the microbial richness and composition of long-term oil contaminated soil microbial communities. Upon taxonomic analysis using different approaches (RDP classifier and LCA algorithm), Proteobacteria was the well-represented phylum along with $\beta-, \alpha-, \gamma_{-}$, and $\delta$-Proteobacteria. This group of bacteria has considerable morphological, physiological and metabolic diversity, which are of great importance to global carbon, nitrogen and sulfur cycling [50]. Bacteroidetes are the second most prevalent group of bacteria detected in polluted sample, with three major classes (Sphingobacteria, Cytophagia and Flavobacteriia). Gammaproteobacteria is dominant group of bacteria followed by $\beta-, \alpha$-Proteobacteria in pristine soil sample. The results showed significantly altered microbial community diversity, composition and structure, especially for particular microbial populations at class level.

The members of the Proteobacteria phylum are a group of Gram-negative bacteria that have an important role in decomposition of organic matter and carbon cycling [53]; Neisseriaceae and Burkholderiaceae were found to be major families. Proteobacteria has been previously detected at high abundance in soil samples, including polluted ones [55-58], and shift in their community were also observed upon contamination with oil or during bioremediation. While, Proteobacteria accounted for $60 \%$ of total sequences in our polluted soil sample, they accounted for $86 \%$ in long-term dieselcontaminated soil from Poland [58], $45 \%$ in contaminated permafrost soils along a crude oil pipeline in china [59], $42 \%$ in gradient of petroleum contaminated desert soil [17] and 50-60\% in contaminated mangrove sediments from Brazil [57]. Members of Betaproteobacteria and Gammaproteobacteria are known to be highly versatile for their degradation ability [7, 60,61]. The strains of genera Chromobacterium, Xanthomonas, Pseudomonas, Burkholderia and Acenitobacter which prevailed the classes Betaproteobacteria and Gammaproteobacteria were found to possess oil-degrading capabilities $[17,18,22]$. Various microbial populations that are capable of degrading different oil and petroleum products including species of Pseudomonas, Flavobacterium, Arthrobacter, Alcaligenes, Nocardia, Micrococcus, Corynebacterium and Mycobacterium have been isolated from soil [62], while Pseudomonas, Arthrobacter, Sphingomonas, Rhodococcus, Ochrobactrum, Psychrobacter, Pseudoalteromonas, Acinetobacter and Bacillus are isolated from marine environment [63-66]. Among the detected genera known for degradation are Actinobacteria, Microbacterium and Micrococcus [40, 67].

Rarefaction analysis for particular ecosystem is a prerequisite to deduce the complete taxonomic profile of the community. The rarefaction curves are nearly reaching saturation for classifications based on RDP. Moreover, results from PCA plot, CA plot and contour plot also suggested there is variation in community structure for both samples and appropriate depth of sampling is also covered. Mapping of metagenome reads onto bacterial genomes suggested that organisms related to the identified species were enriched at the site contaminated with oil and presumably play an active role in biodegradation.

Understanding the factors that influence microbial community structure is an important goal in microbial ecology [51]. Our analysis results indicate that oil has a significant impact on soil microbial functional communities in contaminated soil. On one hand oil contamination could be toxic to many microbial populations reducing microbial diversity and on the other hand, the vast range on carbon substrates and subsequent metabolites present in oilcontaminated soil could facilitate the development of rather complex microbial communities. In this study, microbial functional genes encoded for lipid metabolism was analyzed using KEEG database [39]. The 


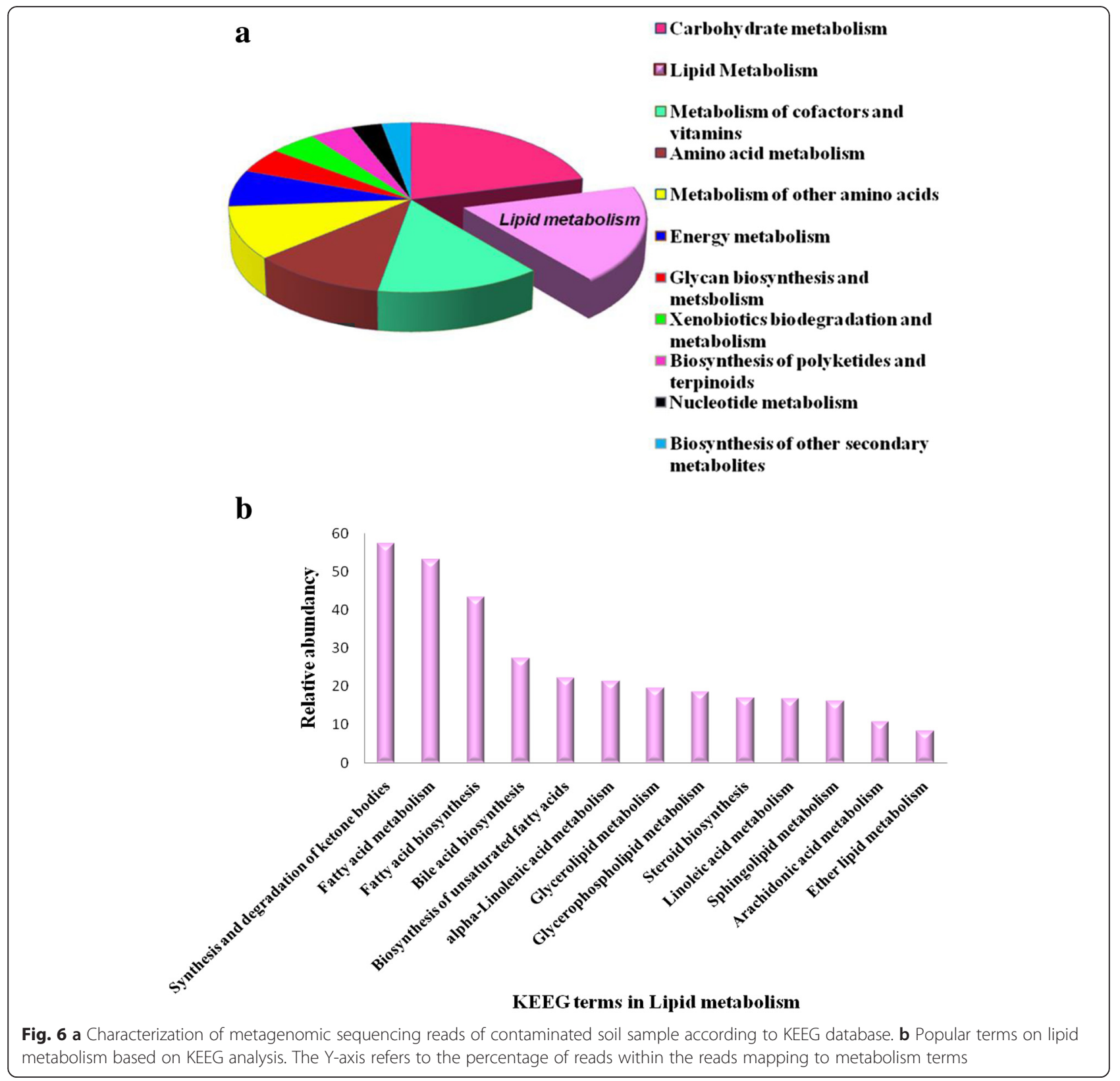

pathways of fatty acid biosynthesis and the enzymes involved in them are well conserved. The abundance of several functional genes involved in fatty acid synthesis and metabolism such as $a c c, f a b$ and fad genes were detected. These genes are directly involved in the synthesis and metabolism of free fatty acids [68]. The increase in these functional genes might be due to the natural selection of organisms capable of utilizing fatty acids/lipids. The degradation of PAHs by microorganisms through a complex enzymatic process was well documented by Patel et al. [63] with increase in frequencies of $n a h A$ genes in polluted water. Bestawy et al. [22] reported a positive correlation between oil contamination and abundance of $f a b$ genes from gram-negative bacteria removing oil and grease in industrial effluent.

Metabolic pathway analysis for fatty acid biosynthesis

Fatty acid biosynthesis in almost all the organisms culminates in formation of saturated fatty acids. All organisms produce fatty acids via a repeated cycle of reactions involving the condensation, reduction, dehydration and reduction of carbon-carbon bonds. First step in fatty acid biosynthesis (Fig. 7) is the ATP dependent formation of malonyl-CoA from acetyl-CoA and bicarbonate by acetyl-CoA carboxylase (acc, EC 6.4.1.2) enzyme. All 
Table 4 Abundance of enzymes mapped from metagenomic reads identified in KEEG database

\begin{tabular}{lll}
\hline Sr. No & Enzyme mapped & Abundance/Hits \\
\hline 1 & ABC transporter related & 237 \\
2 & $\begin{array}{l}\text { binding-protein-dependent transport systems } \\
\text { inner membrane component }\end{array}$ & 192 \\
3 & TonB-dependent receptor & 186 \\
4 & TonB-dependent receptor plug & 141 \\
5 & short-chain dehydrogenase/reductase SDR & 119 \\
6 & acriflavin resistance protein & 118 \\
7 & ABC transporter related protein & 116 \\
8 & NAD-dependent epimerase/dehydratase & 114 \\
9 & oxidoreductase domain protein & 104 \\
10 & sulfatase & 94 \\
11 & protein of unknown function DUF214 & 90 \\
12 & transcriptional regulator & 80 \\
13 & histidine kinase & 76 \\
14 & ABC transporter ATP-binding protein & 69 \\
15 & extracellular solute-binding protein & 69 \\
16 & inner-membrane translocator & 69 \\
17 & aldo/keto reductase & 68 \\
18 & AMP-dependent synthetase and ligase & 64 \\
19 & beta-lactamase & 64 \\
20 & glycoside hydrolase family protein & 64 \\
\hline & & \\
\hline
\end{tabular}

bacterial organisms contain a type II synthase (FAS II) for which each reaction is catalyzed by a discrete protein and reaction intermediates are carried in the cytosol as thioesters of the small acyl carrier protein (ACP) [45]. Malonyl CoA:ACP transferase encoded by $f a b D$ gene (EC 2.3.1.39) undergoes transacylation of malonyl from
CoA to ACP. The chain elongation step in fatty acid biosynthesis consists of the condensation of acyl groups, which are derived from acyl- CoA or acyl-ACP, with malonyl-ACP by two types of 3-ketoacyl-ACP synthases. The first class of 3-ketoacyl-ACP synthase III ( $f a b H$, EC 2.3.1.180) is responsible for the initiation of fatty acid elongation and utilizes acyl-CoA primers. The second class of enzymes ( $f a b F$ EC 2.3.1.179 and $f a b B$, EC 2.3.1.41) is responsible for the subsequent rounds of fatty acid [68-70]. Thus, produced acyl-ACP is catalyzed by three enzymes [NADPH-dependent 3-ketoacyl-ACP reductase (f $a b G, \mathrm{EC}$ 1.1.1.100), 3-hydroxyacyl-ACP dehydratase (fabZ, EC 4.2.1.59) and NAD(P)H-dependent enoyl-ACP reductase (fabI, EC 1.3.1.9, 1.3.1.10)] for reduction, dehydration and reduction of carbon-carbon bonds,respectively. Further, additional cycles are initiated by $f a b F$ and $f a b B$. The $f a d R_{E c}$ protein is a global regulator of fatty acid degradation, is a transcriptional activator that binds to the fabA promoter region [71].

Finally, input to fatty acid synthesis is acetyl CoA and the output is free fatty acid synthesis. The $f a b$ and fad proteins are highly conserved in many grampositive bacteria including Bacillus, Clostridium, Streptomyces and other related genera [70-72]. Moreover, its orthologues are unexpectedly present in more diverse genera, such as Metanosarcina (Archaea), and Bordetella, Burkholderia and Chromobacteria ( $\beta$-proteobacteria) [70]. Also, genome analysis indicated that only the $\alpha-, \beta$ and $\gamma$-proteobacteria have the proteins of this pathway [73, 74].

\section{Bacterial isolates by culture dependent approach}

Using culturable approach higher number of total bacterial count was observed in presence of tributyrin from

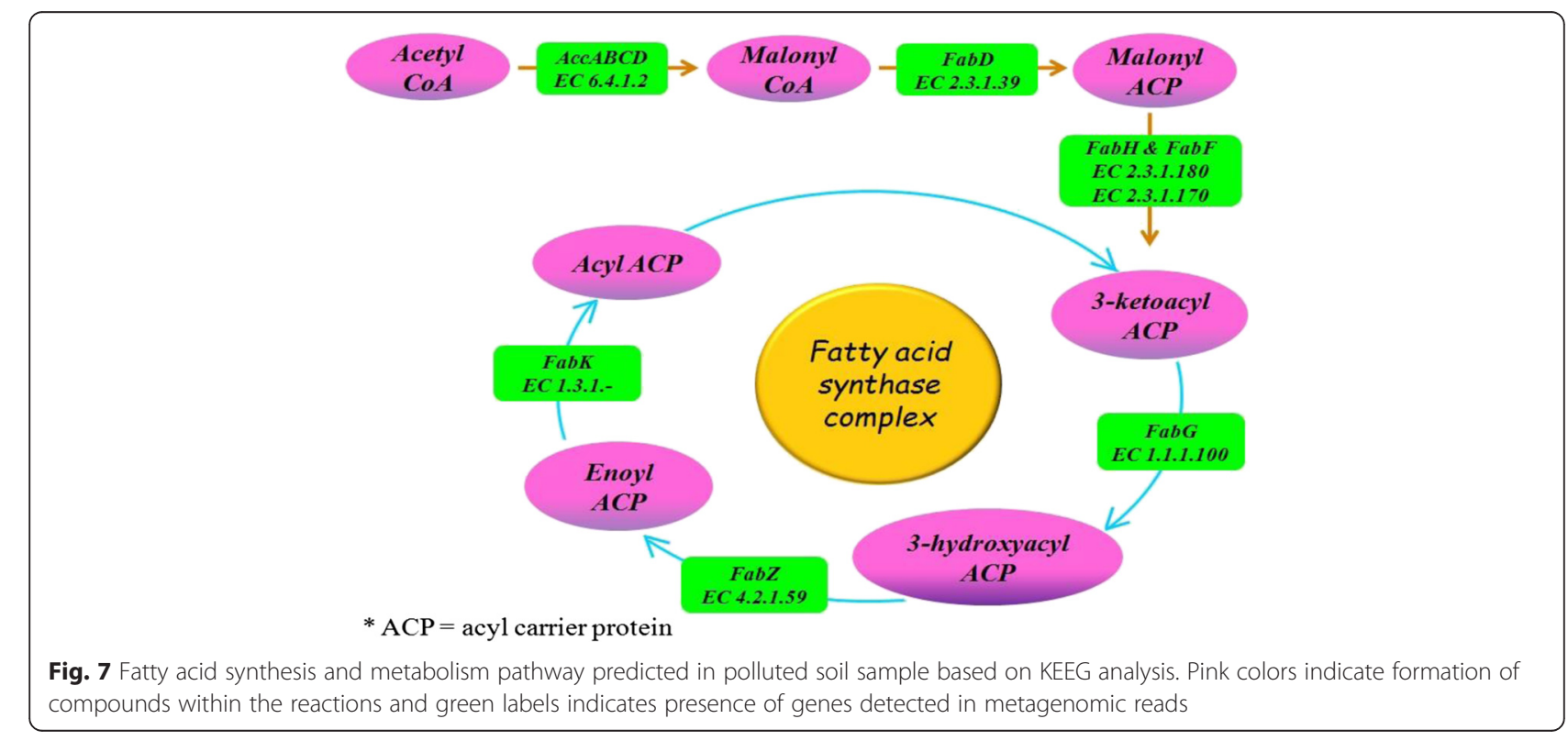


polluted environment in comparison to that of pristine. Result clearly indicates the adaption of organism toward oil stress. Biodegradation by intrinsic microbial populations is the key and reliable system through which thousands of organic contaminants are eradicated from the environment [75]. Different species of Bacillus (B. subtilis, B. pumilis, B. endophyticus) and Pseudomonas (P. stutzeri, Pseudomonas sps.) were found in abundance from oil stressed soil which depicts their significant role in degradation of oil. These microbial strains have ability for producing extracellular lipase enzymes that hydrolyze triglycerides (the main component of oils and fats) to fatty acids and glycerol [21, 22]. The enzymatic versatility of these bacteria is well known and has been suggested as their importance in ecosystem. As noted by Ahmad et al., Bacillus strains play an important role in biodegradation of oil contaminated soil in combination with that of Pseudomonas sp [41]. Apart from this species such as B. thuringiensis, Micrococcus sp, Corynebacterium sp., and Acinetobacter sp. also has significant role in degradation of pollutants [75, 76].

\section{Conclusion}

In conclusion, present study reflects the detection of microbial diversity across oil stress condition favouring $\beta$ proteobacteria such as Chromobacterium, Xanthomonas, Pseudomonas, Burkholderia and Acinetobacter sp. The microbial community analysis at the metagenome level gives an insight into the repertoire of species to deal with oil contamination. We also observed, genes corresponding to enzymes involved in a wide variety of reactions and operating in many unrelated biosynthesis pathways collaborates well with the fact that the site of study has long-term oil contamination. Moreover, the isolation of different genera of $\beta$-proteobacteria is in correspondence with results obtained by culture dependent approach reporting abundance of $\beta$-proteobacteria in polluted samples. These isolates are well documented for biodegradation processes. In this regard, obtained knowledge will be useful in understanding the pathways for synthesis and metabolism of fatty acids released for oils and the microbial communities dominating in such stress condition.

\section{Availability of supporting data}

The sequence data for both soil samples i.e. polluted and control obtained from Ion Torrent PGM platform has been deposited at MGRAST server (version 3). MGRAST IDs for the datasets are 4508969.3 and 4516462.3 for polluted soil and control soil, respectively. MGRAST IDs for the contig obtained from both the samples are 4515485.3 and 4512472.3 , respectively. The DOI link for the server is http://metagenomics.anl.gov/ metagenomics.cgi?page $=$ Home . The sequences obtained from the culturable diversity study have been submitted to GenBank, NCBI and their accession numbers are from KR140170 to KR140186 (polluted soil) and KR140187 to KR140201 (control soil). The DOI link for GenBank is http://www.ncbi.nlm.nih.gov/genbank.

\section{Additional file}

\begin{abstract}
Additional file 1: Figure S1. Metagenomic DNA extracted from polluted as well as control soil sample and electrophoresed on $0.8 \%$ agarosa gel. Lane $M$ is of marker, Lane 1, is for polluted sample (representing pooled metagenomic DNA for $\mathrm{P} 1+\mathrm{P} 2+\mathrm{P} 3=\mathrm{P}$ ) and Lane 2 is for control soil sample (representing pooled metagenomic DNA for C1+ $\mathrm{C} 2+(3=\mathrm{C})$. Figure $\mathbf{S 2}$. Distribution of taxa among bacteria at rank phylum classified according to 165 rDNA using RDP classifier for both polluted as well as control sample. Figure S3. Distribution of taxa among bacteria at rank phylum classified according to lowest common ancestor (LCA) for both polluted as well as control sample. Figure S4. Comparative distribution of taxa among bacteria at rank class classified according to WebCARMA and M5NR datasets for both polluted as well as control sample. Table S1. Enzymes mapped for lipid metabolism pathways in KEEG database. (DOC 300 kb)
\end{abstract}

\section{Competing interests}

All the authors declare that they have no competing interest. DNA sequencing was carried out as outsourcing by Xcelris Lab Pvt. Ltd.

\section{Authors' contributions}

Conceived and designed the experiments: DM. Performed the experiments: VP Analyzed the data: VP AS RL. Contributed reagents/materials/analysis tools: RL, NAA-D. Wrote the paper: VP DM. Sample Collection: VP DM All authors read and approved the final version of the manuscript.

\section{Acknowledgments}

We are grateful to University Grants Commission (UGC) grant no. F.42-167/ 2013(SR) and Department of Biotechnology (DBT) sponsored Centre of Excellence and Innovation in Biotechnology (CEIB) programme supported grant no. BT/01/CEIB/09/N/05 for financial assistance. Vice Deanship of Research Chair, King Saud University, Kingdom of Saudi Arabia is duly acknowledged.

\section{Author details}

${ }^{1}$ Post Graduate Department of Biosciences, Centre of Advanced Study in Bioresource Technology, Sardar Patel University, Satellite Campus, Vadtal Road, Bakrol 388 315, Gujarat, India. ²Department of Zoology, University of Delhi, Delhi, India. ${ }^{3}$ Department of Botany and Microbiology, Addiriya Chair for Environmental Studies, College of Science, King Saud University, P.O. Box \# 2455, Riyadh 11451, Saudi Arabia.

Received: 10 September 2015 Accepted: 9 March 2016

Published online: 22 March 2016

\section{References}

1. Desai C, Pathak H, Madamwar D. Advances in molecular and "-omics" technologies to gauge microbial communities and bioremediation at xenobiotic/anthropogen contaminated sites. Bioresour Technol. 2010;101: 1558-69.

2. Bhattacharya D, Sarma P, Krishnan S, Mishra S, Lal B. Evaluation of genetic diversity among Pseudomonas citronellolis strains isolated from oily sludgecontaminated sites. Appl Environ Microbiol. 2003;69:1435-41.

3. Maila M, Randima P, Dronen K, Cloete T. Soil microbial communities: Influence of geographic location and hydrocarbon pollutants. Soil Biol Biochem. 2006;38:303-10.

4. Hamamura N, Olson S, Ward D, Inskeep W. Microbial population dynamics associated with crude-oil biodegradation in diverse soils. Appl Environ Microbiol. 2006;72:6316-24.

5. Joner E, Johansen A, Loibner A, Cruz M, Szolar O, Portal J, et al. Rhizosphere effects on microbial community structure and dissipation and toxicity of 
polycyclic aromatic hydrocarbons (PAHs) in spiked soil. Environ Sci Technol. 2001;35:2773-7.

6. Nikolaki S, Tsiamis G. Microbial Diversity in the Era of Omic Technologies. 2013; doi:10.1155/2013/958719.

7. Shah V, Zakrzewski M, Wibberg D, Eikmeyer D, Schluter A, Madamwar D. Taxonomic profiling and metagenome analysis of a microbial community from a habitat contaminated with industrial discharges. Microb Ecol. 2013; 66:533-50.

8. Rajendhran J, Gunasekaran P. Microbial phylogeny and diversity: small subunit ribosomal RNA sequence analysis and beyond. Microbiological Res. 2011;166(2):99-110.

9. Gilbert JA, Dupont CL. Microbial metagenomics: beyond the genome. Annual Review of Marine Science. 2011;3:347-71.

10. Venter JC, Remington K, Heidelberg JF, et al. Environmental genome shotgun sequencing of the Sargasso Sea. Science. 2004;304(5667):66-74.

11. Tringe SG, Hugenholtz P. A renaissance for the pioneering $16 \mathrm{~S}$ rRNA gene. Curr Opi Microbiol. 2008;5:442-6.

12. Rusch DB, Halpern AL, Sutton G, et al. The Sorcerer II GlobalOcean Sampling expedition: northwest Atlantic through eastern tropical Pacific. Plos Biology. 2007;5(3):e77.

13. Handelsman J. Metagenomics: application of genomics to uncultured microorganisms. Microbiol Mol Biol Rev. 2004;68:669-85.

14. Al-Saleh E, Drobiova H, Obuekwe C. Predominant culturable crude oildegrading bacteria in the coast of Kuwait. Int Biodeterior Biodegrad. 2009; 63:400-6.

15. Miralles G, Nerini D, Mante C, Acquaviva M, Doumenq P, et al. Effects of spilled oil on bacterial communities of Mediterranean coastal anoxic sediments chronically subjected to oil hydrocarbon contamination. Microb Ecol. 2007:54:646-61.

16. Orcutt BN, Joye SB, Kleindienst S, Knittel K, Ramette A, et al. Impact of natural oil and higher hydrocarbons on microbial diversity, distribution, and activity on Gulf of Mexico cold-seep sediments. Deep Sea Res Part2 Top Stud Ocean org. 2010;57:2008-21.

17. Raeid MM, Al-Kindi S, Al-Kharusi S. Diversity of bacterial communities along a petroleum contamination gradient in desert soils. Microb Ecol. 2015;69: 95-105.

18. Raeid MM, Al-Kharusi S, Al-Hinai M. Effect of biostimulation, temperature and salinity on respiration activities and bacterial community composition in an oil polluted desert soil. Int Biodeterior Biodegrad. 2015;98:43-52.

19. Radwan S. Microbiology of oil-polluted contaminated desert soils and coastal areas in the Arabian Gulf Region. In: Dion P, Nautiyal CS, editors. Microbiology of extreme soils. Soil biology 13. Berlin: Springer; 2008. p. 275-98.

20. Radwan S. Phytoremediation for oily desert soils. In: Singh A, Kuhad RC, Ward OP, editors. Advances in applied bioremediation. Berlin: Springer; 2009. p. 279-98

21. Karigar CS, Rao SS. Role of microbial enzymes in the bioremediation of pollutants: A review. Enzym Res. 2011. doi:10.4061/2011/805187.

22. Bestawy E, Mohamed H, Nawal E. The potentially of free gram-negative bacteria for removing oil and grease from contamination industrial effluents. World J Microbiol Biotechnol. 2005;21:815-22.

23. Riffaldi R, Minzi R, Cardelli R, Palumbo S, Saviozzi A. Soil biological activities in monitoring the bioremediation of diesel oil contaminated soil. Water, Air and Soil pol. 2006;170:3-15.

24. Zhou J, Bruns MA, Tiedje JM. DNA recovery from soils of diverse composition. Appl Environ Microbiol. 1996;62:316-22.

25. Desai C, Parikh R, Vaishnav T, Shouche Y, Madamwar D. Tracking the influence of long-term chromium pollution on soil bacterial community structures by comparative analyses of 165 rRNA gene phylotypes. Res Microbiol. 2009;160:1-9.

26. Ludwig W, Strunk O, Westram R, Richter L, Meier H, Yadhukumar BA, Lai T, Steppi S, Jobb G, Forster W, et al. ARB: a software environment for sequence data. Nucleic Acids Res. 2004;32:1363-71.

27. Zerbino DR, Birney E. Velvet: Algorithms for de novo short read assembly using de Bruijn graphs. Genome Res. 2008;18:821-9.

28. Huson DH, Auch AF, Qi J, Schuster SC. Megan analysis of metagenomic data. Genome Res. 2007;17:377-86.

29. Wang Q, Garrity GM, Tiedje JM, Cole JR. Naïve Bayesian classifier for rapid assignment of rRNA sequences into the new bacterial taxonomy. Appl Environ Microbiol. 2007;73:5261-7.
30. Clemente JC, Jansson J, Valiente G. Accurate taxonomic assignment of short pyrosequencing reads. Pac Symp Biocomput. 2010;24:3-9.

31. Cole JR, Wang Q, Cardenas E, Fish J, Chai B, Farris RJ. The Ribosomal Database Project: improved alignments and new tools for rRNA analysis. Nucleic Acids Res. 2009;37:D141-5,

32. Wani AA, Surakasi VP, Siddharth J, Raghavan RG, Patole MS, Ranade D, Shouche YS. Molecular analyses of microbial diversity associated with the Lonar soda lake in India: An impact crater in a basalt area. Res Microbiol. 2006:157:928e937.

33. Kapley A, Baere TD, Purohit HJ. Eubacterial diversity of activated biomass from a common effluent treatment plant. Res Microbiol. 2007;158:494e500.

34. Hammer O, Harper DAT, Ryan PD. PAST: Paleontological statistics software package for education and data analysis. Palaeontol Electron. 2001; $4(1): 9$

35. Albertsen M, Hugenholtz P, Skarshewski A, Nielsen KL, Tyson GW, Nielsen $\mathrm{PH}$. Genome sequences of rare, uncultured bacteria obtained by differential coverage binning of multiple metagenomes. Nat Biotechnol. 2013;31(6): 533-8.

36. Krzywinski M, Schein J, Birol I, Connors J, Gascoyne R, Horsman D, Steven J, Marco A. Circos: An information aesthetic for comparative genomics. Genome Res. 2009:19:1639-45.

37. Rho $\mathrm{M}$, Tang $\mathrm{H}$, Ye $\mathrm{Y}$. FragGeneScan: predicting genes in short and errorprone reads. Nucleic Acids Res. 2010;38:20-191.

38. Tatusov RL, Galperin MY, Natale DA, Koonin EV. The COG database: a tool for genome-scale analysis of protein functions and evolution. Nucleic Acids Res. 2001;28:33-6.

39. Ogata H, Goto S, Sato K, Fujibuchi W, Bono H, Kanehisa M. KEGG: Kyoto Encyclopedia of Genes and Genomes. Nucleic Acids Res. 1999;27:29-34.

40. Ilori MO, Amund D, Robinson CK. Ultrastructure of two oil degrading bacteria isolated from the tropical soil environment. Folia Microbiol. 2000:45. 259-62.

41. Ahmad M, Sajjad W, Rehman ZU, Hayat M, Khan I. Identification and characterization of intrinsic petrophillic bacteria from oil contaminated soil and water. Int J Curr Microbiol App Sci. 2015:4(2):338-46.

42. Kumar D, Kumar L, Nagar S, Raina C, Prasad R, Gupta VK. Screening isolation and production of lipase/esterase producing Bacillus sp. Strain DVL2 and its potential evaluation in esterification and resolution reaction. Arc Appl Sci Res. 2012:4(4):1763-70.

43. Sangwan N, Lata P, Dwivedi V, Singh A, Niharika N, et al. Comparative metagenomic analysis of soil microbial communities across three hexachlorocyclohexane contamination levels. Plos ONE. 2012;7(9):e46219. doi:10.1371/journal.pone.0046219.

44. Li A, Chu Y, Wang X, Ren L, Yu J, Liu X, Yan J, Zhang L, Wu S, Li S. A pyrosequencing based metagenomic study of methane-producing microbial community in solid-state biogas reactor. Biotechnol for Biofuels. 2013;6:3.

45. DeLong EF, Preston CM, Mincer T, Rich V, Hallam SJ, Frigaard NU, et al. Community genomics among stratified microbial assemblages in the oceans interior. Science. 2006;311:496-503.

46. Janssen PH. Identifying the dominant soil bacterial taxa in libraries of 165 rRNA and 16S rRNA genes. Appl Environ Microbiol. 2006;72:1719-28.

47. Lesaulnier C, Papamichail D, McCorkle S, Ollivier B, Skiena S, Taghavi S, et al. Elevated atmospheric $\mathrm{CO}_{2}$ affects soil microbial diversity associated with trembling aspen. Environ Microbiol. 2008;10:926-41.

48. Patel V, Munot H, Shouche Y, Madamwar D. Response of bacterial community structure to seasonal fluctuation and anthropogenic pollution on coastal water of Alang-Sosiya ship breaking yard, Bhavnagar. India Bioresour Technol. 2014;161:362-70.

49. DeAngelis KM, Brodie EL, DeSantis TZ, Andersen GL, Lindow SE, Firestone MK. Selective progressive response of soil microbial community to wild oat roots. ISME J. 2009;3:168-78.

50. Zhili $H$, Piceno $Y$, Ye D, Meiying $X$, et al. The phylogenetic composition and structure of soil microbial communities shifts in response to elevated carbon dioxide. ISME J. 2012;6:259-72

51. Liang Y, Joy D, Nostrand V, Deng Y, Zhili H, Liyou W, Xu Z, Guanghe L, Zhou J. Functional gene diversity of soil microbial communities from five oilcontaminated fields in China. ISME J. 2011;5:403-13.

52. Yang $Y$, Gao Y, Wang $S, X u D, Y u ~ H$. The microbial gene diversity along an elevation gradient of the Tibetan grassland. ISME J. 2014;8:430-40.

53. Campbell BJ, Polson SW, Hanson TE, Mack MC, Schuur EAG. The effect of nutrient deposition on bacterial communities in Arctic tundra soil. Environ Microbiol. 2010;12:1842-54. 
54. Shade A, Capraso JG, Handelsman J, Knight R, Fierer N. A meta-analysis of changes in bacterial and archaeal communities with time. ISME J. 2013;7: 1493-506.

55. Kersters K, De Vos P, Gillis M, Swings J, Vandamme P, Stackebrandt E. Introduction to the Proteobacteria. In: Dwarkin M, Falkow S, Rosenberg E, Schleifer K-H, Stackebrandt E, editors. The Prokaryotes, 5. 3rd ed. New York: Springer; 2006. p. 3-37.

56. Adetutu EM, Smith RJ, Weber J, Aleer S, Mitchell JG, Ball AS, Juhasz AL. A polyphasic approach for assessing the suitability of bioremediation for the treatment of hydrocarbon impacted soil. Sci Total Environ. 2013;450-451: $51-8$.

57. dos Santos HF, Cury JC, do Carmo FL, dos Santos AL, Tiedje J, van Elsas JD Rosado AS, Peixoto RS. Mangrove bacterial diversity and the impact of oil contamination revealed by pyrosequencing: bacterial proxies for oil pollution. PloS ONE. 2011;6.

58. Sutton NB, Maphosa F, Morillo JA, Abu Al-Soud W, Langenhoff AAM, Grotenhuis T, Rijnaarts HHM, Smidt H. Impact of long-term diesel contamination on soil microbial community structure. Appl Environ Microbiol. 2013;79:619-30.

59. Yang $\mathrm{S}$, Wen $\mathrm{X}$, Jin $\mathrm{H}$, Wu Q. Pyrosequencing investigation into the bacterial community in permafrost soils along the China-Russia crude oil pipeline (CRCOP). PLoS One. 2012;7:e52730.

60. Alonso-Gutierrez J, Costa MM, Figueras A, Albaiges J, Vinas M, Solanas AM, Novoa B. Alcanivorax strain detected among the cultured bacterial community from sediments affected by the 'Prestige' oil spill. Mar Ecol Prog Ser. 2008;362:25-36

61. Kostka JE, Prakash O, Overholt WA, Green SJ, Freyer G, Canion A, Delgardio J, Norton N, Hazen TC, Huettel M. Hydrocarbon degrading bacteria and the bacterial community response in Gulf of Mexico beach sands impacted by the deepwater horizon oil spill. Appl Environ Microbiol. 2011;77:7962-74.

62. Malik Z, Ahmed S. Degradation of petroleum hydrocarbons by oil field isolated bacterial consortium. African J Biotechnol. 2014;11(3):650-8.

63. Patel V, Patel J, Madamwar D. Biodegradation of phenanthrene in bioaugmented microcosm by consortium ASP developed from coastal sediment of Alang-Sosiya ship breaking yard. Mar Pollut Bull. 2013;74: 199-207.

64. Hou D, Shen X, Luo Q, He Y, Wang Q, Liu Q. Enhancement of the diesel oil degradation ability of a marine bacterial strain by immobilization on a novel compound carrier material. Mar Pollut Bull. 2012;67:146-51.

65. Song $X, X u Y$, , Li G, Zhang Y, Huang T, Hu Z. Isolation, characterization of Rhodococcus sp. P14 capable of degrading high-molecular-weight polycyclic aromatic hydrocarbons and aliphatic hydrocarbons. Mar Pollut Bull. 2011;62: 2122-8

66. Arulazhagan $\mathrm{P}$, Vasudevan N. Role of a moderately halophilic bacterial consortium in the biodegradation of poly aromatic hydrocarbons. Mar Pollut Bull. 2009;58:256-62.

67. Prince R, Gramain A, Mc Genity T. Prokaryotic hydrocarbon degraders. In Timmis K, editor. Handbook of hydrocarbon and lipid microbiology. Berlin: Springer; 2010. p. 1672-92.

68. Campbell JW, Cronan JE. Bacterial fatty acid biosynthesis: Targets for Antibacterial Drug Discovery. Annu Rev Microbiol. 2001:55:305-32.

69. Waltermann M, Steinbüchel A. Neutral lipid bodies in prokaryotes: recent insights into structure, formation, and relationship to eukaryotic lipid depots. J Bacteriol. 2005;187:3607-19.

70. Sampath $\mathrm{H}$. Polyunsaturated fatty acid regulation of genes of lipid metabolism. Annu Rev Nutr. 2005;25:317-40.

71. Fujita Y, Matsuoka H, Hirooka K. Regulation of fatty acid metabolism in bacteria. Mol Microbiol. 2007;66(4):829-39.

72. Matsuoka H, Hirooka K, Fujita Y. Organization and function of the YsiA regulon of Bacillus subtilis involved in fatty acid degradation. J Biol Chem. 2007;282:5180-94

73. Cronan JE, Subrahmanyam S. FadR, transcriptional co-ordination of metabolic expediency. Mol Microbiol. 1998;29:937-43.

74. Cronan Jr JE, Waldrop GL. Multi-subunit acetyl-CoA carboxylases. Prog Lipid Res. 2002:41:407-35

75. Cappello S, Caruso G, Zampino D, Monticelli LS, Maimone G, et al. Microbial community dynamics during assay of harbor oil spill bioremediation: a microscale stimulation study. J Appl Microbiol. 2007;122:184-94.

76. Archaya S, Gopinath LR, Sangaatha S, Bhuvaneshwari R. Molecular characterization of kerosene degrading bacteria isolated from kerosene polluted soil. Int J Adv Res. 2014;2(4):1117-24.

\section{Submit your next manuscript to BioMed Central and we will help you at every step:}

- We accept pre-submission inquiries

- Our selector tool helps you to find the most relevant journal

- We provide round the clock customer support

- Convenient online submission

- Thorough peer review

- Inclusion in PubMed and all major indexing services

- Maximum visibility for your research

Submit your manuscript at www.biomedcentral.com/submit 